\title{
Molecules and morphology reveal cryptic variation among digeneans infecting sympatric mullets in the Mediterranean - CORRIGENDUM
}

ISABEL BLASCO-COSTA, JUAN ANTONIO BALBUENA, JUAN ANTONIO RAGA, ANETA KOSTADINOVA and PETER D. OLSON

doi:10.1017/S0031182009991375, Published online by Cambridge University Press, 23 October 2009.

The authors regret that Fig. 4A-B of the above article was published with an error such that the light grey circles intended to represent 'Morphotype 2' were missed off the figure in the online PDF and printed versions.

The corrected version appears below.
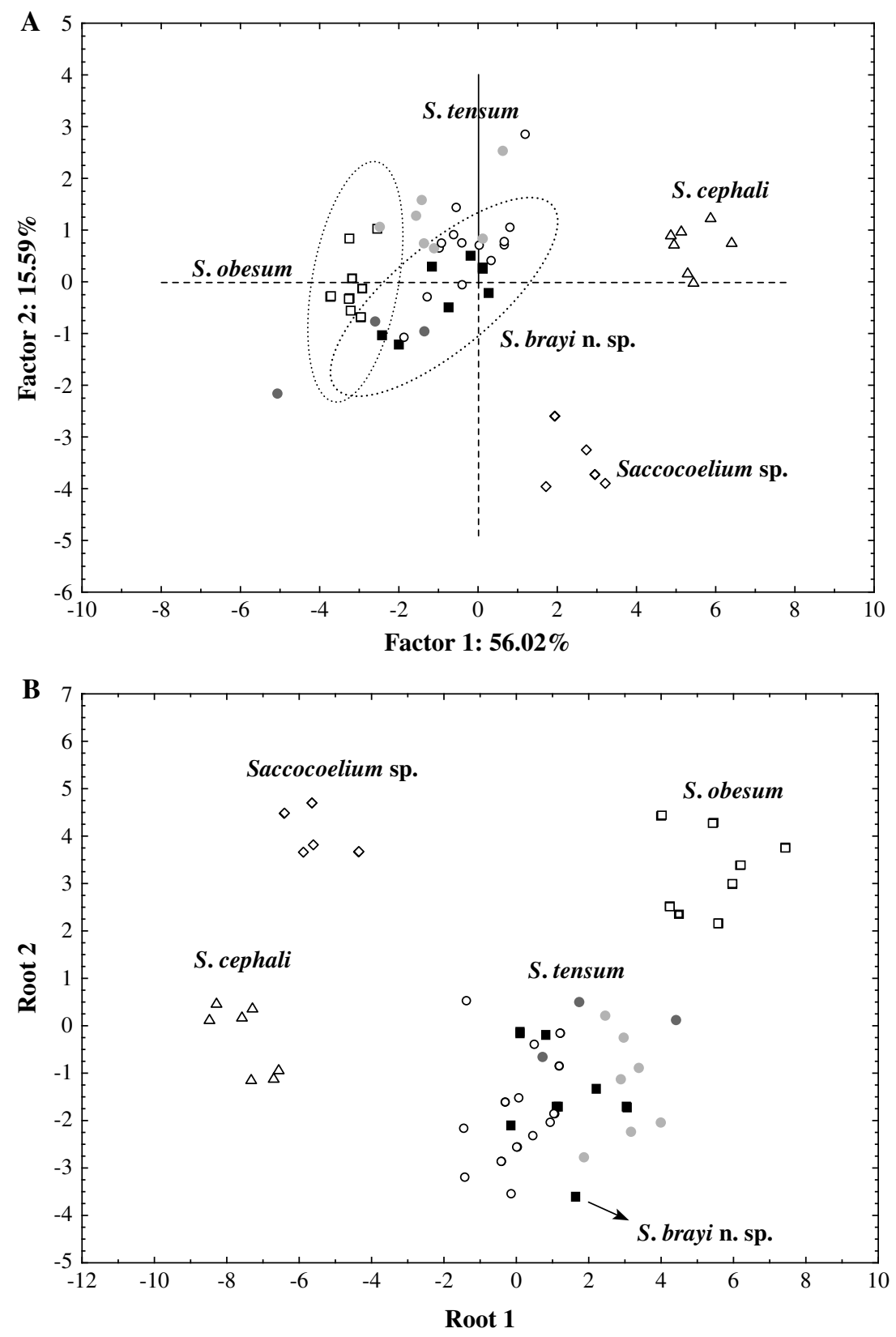